\title{
Operating room nurse residency and specialty educators: Paramount in the success of novice nurse retention
}

\author{
LaSandra Brown, Debbie Belgard, Nakeisha Washington, Sparkle Grueso \\ Houston Methodist Hospital, Houston, Texas, United States
}

Received: June 27, 2017

Accepted: November 9, 2017 Online Published: December 18, 2017

DOI: $10.5430 /$ jnep.v8n5p20

URL: https://doi.org/10.5430/jnep.v8n5p20

\begin{abstract}
Perioperative service is one of the specialties of nursing in which a team approach is vital for optimal patient care. The registered nurse is responsible for coordinating and delivering safe patient care. Operating room (OR) nurses are responsible for applying fundamental applications of the nursing process while formulating plans of care unique to surgical patients. The growing shortage of nurses worldwide especially impacts highly complex areas such as the OR, where skills specialized are needed to care for patients. One of the largest challenges of a graduate nurse (GN) is becoming enculturated to new environments. Traditionally, OR nursing is a paradigm foreign in nursing curricula; this creates challenges in the GN population in applying their practical nursing skills to surgical patients. In an effort to combat ongoing knowledge deficits unique to OR nursing, Houston Methodist Hospital $(\mathrm{HMH})$ created an OR nurse residency program. The literature suggests that specialty-specific nursing residency programs offer GNs essential tools for becoming successful in their transition. Additionally, research suggests reductions in nurse burnout and turnover rate among GNs with adequate training and preparation. The purpose of this article was to provide insight on the importance of introduction to the OR prior to graduating from nursing school and the importance of OR nursing specialty residency programs and specialty educators as they pertain to the ideal nursing transition, sustainability, retention, and favorable patient outcomes. A questionnaire was created to capture successful applicable practices; the questionnaire also provided an opportunity for GNs to suggest opportunities for program improvements. The questionnaire was used to explore feedback from the summer 2014 Operating Room (OR) residency program graduate nurses in an effort to capture improvements needed for future program success.
\end{abstract}

Key Words: Operating room, Nursing specialty residency program, Sustainability, Favorable patient outcomes

\section{INTRODUCTION}

The average age of nurses, which has led to a growing nursing shortage, is currently a global concern. The demand for nurses is surpassing the supply around the world and especially impacts highly complex areas such as the operating room (OR), where specialized skills are needed to care for patients. ${ }^{[1]}$ Specialty areas such as perioperative nursing are not currently included in undergraduate studies, unlike in diploma programs where nurses are fully trained in the clinical setting in all specialties. It is estimated that nearly $20 \%$ of those currently employed in the perioperative specialty area will retire in the next 5 years. ${ }^{[2]}$ A pipeline by which to create perioperative nurses must be in place if we are to have enough OR nurses. We must partner with universities to

\footnotetext{
*Correspondence: Nakeisha Washington; Email: ndwashington@houstonmethodist.org; Address: Houston Methodist Hospital, 6565 Fannin St., Houston, Texas, United States.
} 
give nursing students a clear understanding of the role of the OR nurse. Television paints an unrealistic picture of what it means to work in the OR. Often this glamorous portrayal of OR nursing is the reason young nurses choose the OR as a career path. One way to bypass this inaccurate picture is to give the students an opportunity to go into the OR and shadow a preceptor. This provides students with a clearer picture of the OR nurse's role. Providing a beginning and a career development program will keep nurses in the OR. ${ }^{[3]}$ Attracting nurses to the OR must begin before the end of nursing school.

The OR is an extremely fast-paced and diverse environment within the nursing specialty. Also, there is a growing issue with retention of nurses after orientation, which is attributed to numerous factors, including the personalities of OR team members, enculturation, complexity of procedures and equipment, and patient populations with multiple co-morbidities and complicated disease states. It is imperative that thorough training and education be provided for the novice nurse to promote safe patient care. A specialty educator with extensive knowledge and experience in the perioperative field is vital to provide consistent foundational didactic instruction and simulation, selection of preceptors, learning experiences, continuous support, and follow through. In an effort to combat the ongoing knowledge deficits unique to OR nursing, Houston Methodist Hospital (HMH) created an OR nurse residency program that is continually refined to stay abreast of growing department needs and evidence-based practice. Recruitment and retention is a twofold process, in which the success of both are vital for sustainability in the perioperative environment, with the ultimate of goal of retention and optimum patient care and outcomes. In conjunction with the residency program, a questionnaire was created to capture successful applicable practices; the questionnaire also provided an opportunity for graduate nurses to suggest opportunities for program improvements. The purpose of this article was to provide insight on the importance of introduction to the OR prior to graduating from nursing school and to introduce OR nursing specialty residency programs and specialty educators as they pertain to the ideal nursing transition, sustainability, retention, and favorable patient outcomes. We also present results from the questionnaire administered to the summer 2014 cohort of nurses, for which 10 of the 11 graduate nurses responded.

\subsection{Background and significance}

The American Nurses Association projects that the nursing shortage will grow to a staggering 1 million RNs by 2020 if the nursing shortage is not aggressively addressed. This figure represents a nursing shortage of $36 \%$ in an environment

Published by Sciedu Press already struggling to keep pace with the demand for nurses at all levels of education and practice. ${ }^{[4]}$ The OR is an underrepresented specialty in the field of nursing. It is perceived as the department behind closed doors in which no one is allowed and for which highly technical skills are required. Planting the idea in the young student beginning in grade school is one way to cultivate future OR nurses. Partnerships with colleges and universities are important to provide a true perspicacity of perioperative nursing. After exposure to and understanding of OR nursing, recruitment efforts are imperative for the selection of appropriate OR nurse orientees. The onboarding process provides the first and lasting impression of the facility and department, as well as the foundational framework the new nurse or employee will build on during their OR career. A dedicated educator and preceptors are required for reinforcement of infrastructure provided during orientation and social integration.

As shown in Figure 1, only 50\% of the respondents to the questionnaire administered to the summer 2014 cohort of nurses in the HMH OR nurse residency program had exposure to the operating room prior to their start in the residency program. Of those respondents, nearly one-third reported that the exposure did not prepare them for enculturation in the unit (see Figure 2).

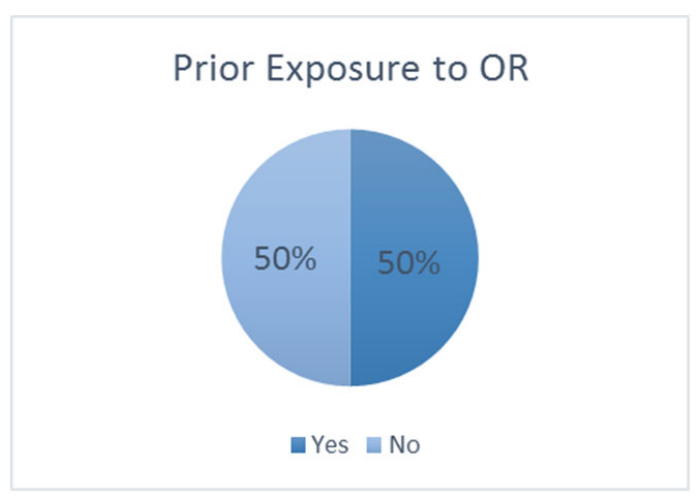

Figure 1. Percentage of respondents who had exposure (university elective, MAPP/student nurse, surgical tech, etc.) to the OR prior to beginning the OR nurse residency program. Abbreviations: MAPP, Houston Methodist Advancement into Professional Practice Program; OR, operating room

\subsection{Review of professional standards, guidelines, and lit- erature}

The Association of periOperative Registered Nurses (AORN) is well aware of the growing nursing shortage, decline in membership, and need for more exposure of the profession of OR nursing. During the national conference in 2015, one of the common themes was exposure and involvement of 
perioperative nurses. In response to the ongoing lack of appropriate perioperative education, a competitive market, and growing expectations in contemporary health care, both AORN and the OR Nurses Association of Canada (ORNAC) have developed comprehensive competency-based curricula for nurses who do not have any experience in the OR. ${ }^{[5]}$ Encouraging the student nurse to pursue OR nursing by providing a program to nurture and educate the novice nurse is one way to create a pipeline for recruitment of OR nurses. After the seed is planted, recruitment efforts are initiated to optimize the selection process for potential candidates. OR orientation and education has to encompass all aspects of perioperative nursing across different spectrums. According to Kai Tiaki Nursing New Zealand, an aim is made to provide a safe learning environment that uses all aspects of training, such as a simulated OR in the clinical skills center. ${ }^{[6]}$ Novice nurses should be provided continuous support throughout their entire orientation process, which may span over 6 to 12 months or more, to ensure retention and return on investment. Identifying immediate barriers prohibiting the novice nurse from obtaining adequate training can potentially reduce turnover rates. According to Penz \& Bassendowski, the nurse educator is a major factor in linking best practices and patient care for novice nurses. ${ }^{[7]}$

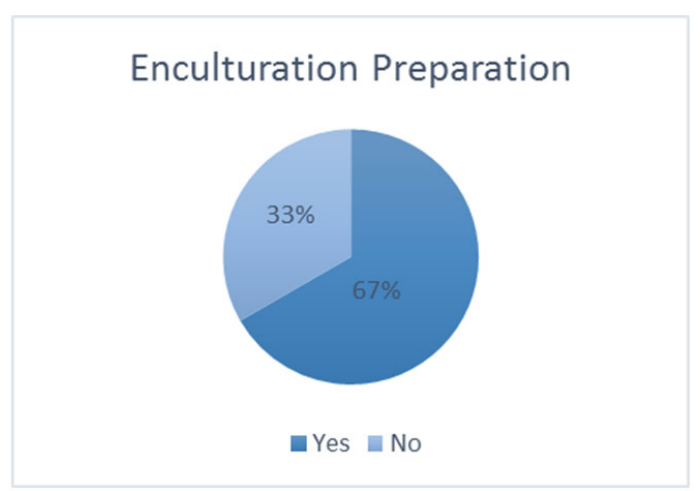

Figure 2. Percentage of respondents with prior exposure who felt prepared for enculturation in the unit

\section{Perioperative nursing as a Career}

According to Battie, the Institute of Medicine report suggests that new education methods, such as transition to practice, nurse residency programs, and bridge programs for $\mathrm{RN}$ to Bachelor of Science in nursing (BSN) transitions, will better prepare nurses to meet patients' changing health care needs as well as changes in the health care delivery system. ${ }^{[8]}$ Those universities that add an elective for OR nursing will provide students an opportunity to graduate with a clear understanding of the role of the OR nurse. Some will know unequivocally that the OR is the career path they want to pursue. Others will know that the OR is not for them, and we view that as a positive outcome. Knowing that the OR is not a career choice will save time and money in the lengthy orientation process. Estimates of the cost of training a nurse for the OR start at $\$ 59,000$ but can rise well above that amount when the cost of the application process, recruitment, and interviewing and hiring processes are included. ${ }^{[2]}$ Those that do choose the OR as a career choice will better acclimate to the OR and the accompanying responsibilities as well as have longer retention.

The rapidly changing and growing health care environment is increasing the need for every specialty. The number of surgeries and surgery specialties is growing and the demand for OR nurses is growing. Behind those closed doors is a misunderstanding of the requirements that a nurse in the OR plays. Often we are asked by a patient what it is that we do. Patients and their families see the surgeon and anesthesia specialists but are confused about the role of the nurse. This is true also for other specialized nurses. Many specialties do not consider the OR as true nursing and encourage new nurses to start out in a medical surgical environment to get their clinical skills and critical thinking skills. That training does not translate into OR nursing and can be considered an unnecessary and wasted step for those who know that the OR is the pathway they want above all other specialties.

Success in recruitment and retention of OR nurses requires a strong support system to give the novice nurse the education and training she or he needs to be comfortable in the role of the OR nurse. At $\mathrm{HMH}$, the OR nurse residency program includes 3 components that work together to recruit and retain nurses: (1) exposure to the OR as an elective during nursing school, (2) an OR residency program, and (3) the unit support necessary in learning the specialty of the OR.

As can be seen in Figure 3, the majority (90\%) of the students in the HMH OR nurse residency program said they received adequate support throughout the program from the educators. This support is integral to the program's efforts to help nurses transition from new hire to competent practice.

\subsection{OR elective}

The OR elective gives the senior nursing students an immersion experience in the OR nurse role. We give the students a short 15-hour didactic phase and 5 simulation hours. After those first few days we give students the dome experience, which is better understood after learning some basic classroom information. The simulation experience, which includes scrub gowning and gloving, surgical prep, back table setup, assessment of a patient, and safety considerations, prepares the student to go into the clinical setting. They 
are excited and nervous at the same time. Each student was assigned a preceptor for a minimum of six months. The preceptor was usually an experienced OR nurse with 1 year or more of OR experience. We encourage the preceptors to allow the students to scrub in at least one time during the week. When the students come to us a year later for application into the OR residency, they can articulate the role of the OR nurse in circulating and scrubbing.

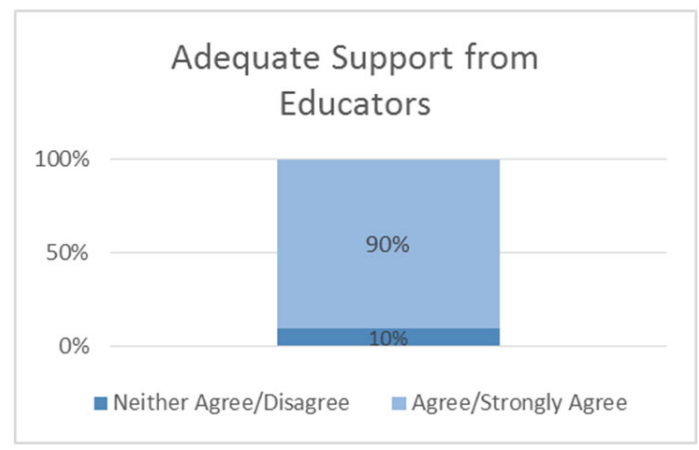

Figure 3. Respondent feedback on whether adequate support was provided throughout the orientation phase from the educators

We prefer to place the students with a previous graduate of the OR elective. That younger and more recent graduate has an understanding of what the student is looking for. Often this preceptor role is not as challenging and is very rewarding. We have past preceptors who request to be included in the simulation and as a preceptor in the OR each year when we have the elective. We recognize how important these preceptors are to the success of this program, and we have been fortunate in having the Magnet experience motivate the nurses in wanting this experience. Thus, it becomes a win-win situation for all concerned.
Students get far more out of this 1 week than we ever imagined. One of the skills that we teach is the meeting of the surgeons. When the students first meet the surgeon, we encourage them to look the surgeon in the eye and very confidently introduce themselves and give their level of expertise. This establishes a relationship that the surgeon understands. Often the surgeon will then spend extra time in teaching and including the student in the surgery. Communication is a vital part of the OR. Simplification and standardization of communication processes and the use of effective communication are ways to improve OR interactions and minimize or prevent errors. ${ }^{[9]}$ Students not only leave the OR elective with a clear understanding of the role of the OR nurse, but also have an opportunity to practice skills under controlled circumstances such as Foley catheter insertion, surgical prep, aseptic technique, and communication with the surgical team. This builds confidence and practices that can be used in other clinical settings and promotes healthy collaboration between physicians and other staff members. ${ }^{[9]}$ With effective institutional curricula and robust supporting hospital orientation programs, there will be financial benefits for hospitals in providing quality care for patients and in retaining OR nurses. ${ }^{[10]}$

The OR immersion experience through the OR elective/nurse residency program provides a multifaceted approach to OR education that enables senior nursing students the ability to obtain first-hand experience beyond the campus as well as prepare them for enculturation. All respondents reported that the majority $(83 \%)$ of the classes and simulations in the OR elective/nurse residency program were important to their success. This finding shows how essential the topics listed in Figure 4 are to the OR and underlines the need for education in each topic.

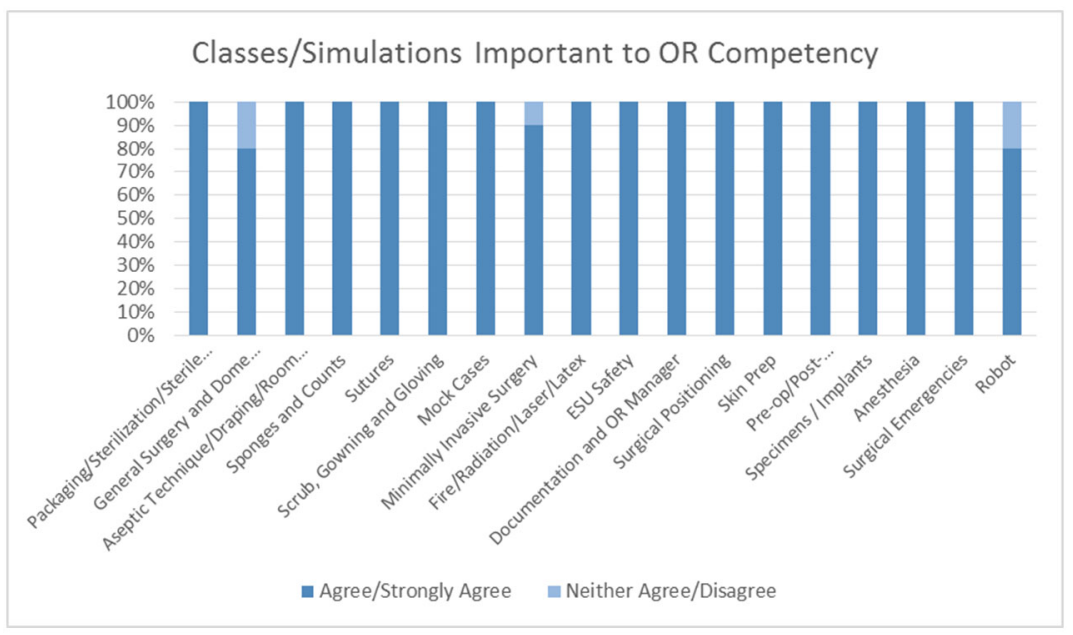

Figure 4. Classes/simulations respondents believed were important to their success in the operating room and were utilized most 


\subsection{OR nurse residency program}

The perioperative educators are an important component of recruitment of novice OR nurses at $\mathrm{HMH}$. The applicants are initially screened by the Human Resources department and perioperative educators to determine if the applicant qualifies for the OR nurse residency program and if an interview with the educators will follow. The initial interview with the perioperative educators will actuate a department observation and leadership interview. During the initial interview, some important attributes that are considered include knowledge of the OR, interest in the OR, personality, short- and longterm goals, and previous exposure via OR elective, surgical technologist, or Methodist Advancement into Professional Practice (MAPP) Student Professional Nurse (SPN) program. After a successful interview with the perioperative educators, an observation is scheduled in up to 2 ORs to determine compatibility between the applicant and the OR. Upon mutual agreement from both, an interview is scheduled with the unit leadership and a final decision is made. The process can be completed in 1 to 2 visits to the facility.
The complete OR nurse residency program averages 6 months, but can expand to over 1 year depending on the specialty. The novice nurses spend the initial 3 weeks of orientation in hospital orientation, OR didactic education, and simulation. During the fourth week, the novice nurses begin orientation in their home departments with one classroom day per week, which extends an additional 3 months. Thereafter, $100 \%$ of the time is spent on the units with their specialty educator. During the initial integration into the department until completion of orientation, proper education and retention are key. This is a vulnerable period, as evidenced in continuous conversations with novice OR nurses.

Content throughout the program was delivered through various mediums, including but not limited to simulations, lectures, handouts, and peer learning. This multidimensional learning approach not only enabled the nurses to obtain imperative skills needed in the OR, but empowered and engaged them as well. As shown in Figure 5, 80\% of the respondents agreed that the delivery method of the content presented was conducive to learning.

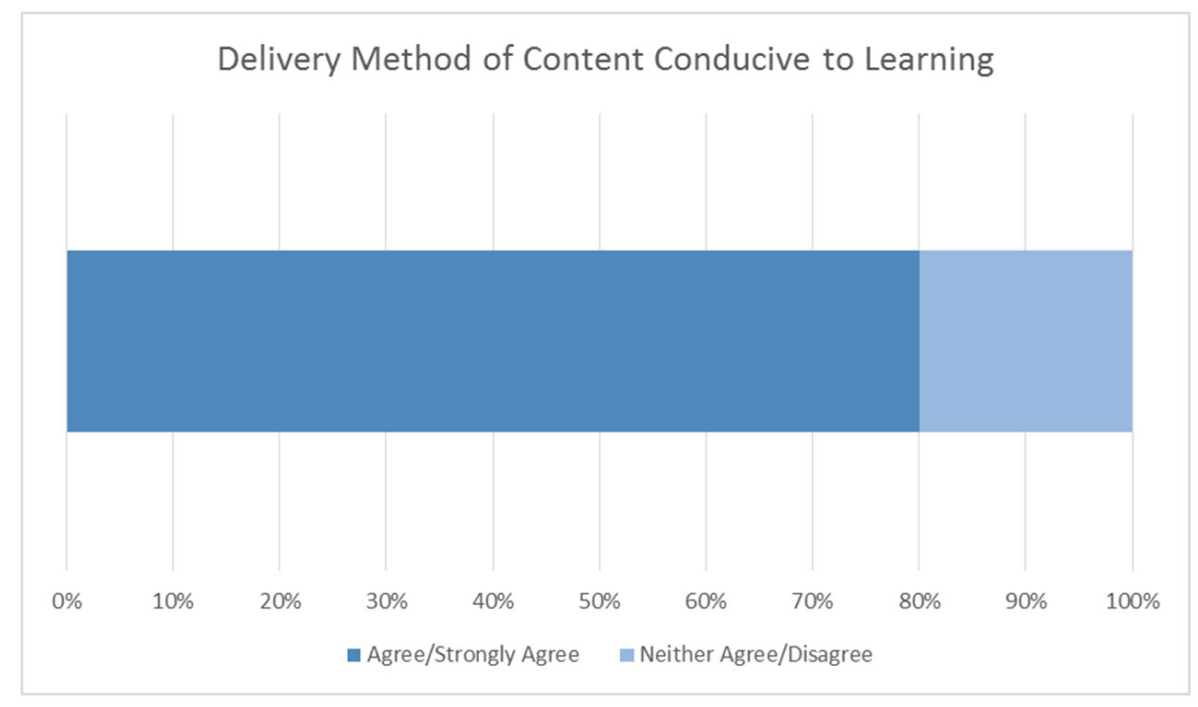

Figure 5. Percentage of respondents who felt the delivery method of content was conducive to learning

\subsection{Specialty perioperative educators}

According to Graling \& Rusynko, there are several reasons it takes so long to prepare a perioperative nurse. ${ }^{[11]}$ These include the following:

- Perioperative nurses expect to be able to function in both scrub and circulator roles;

- The amount of time it takes a novice nurse to develop into a competent perioperative nurse depends on the breadth of knowledge and skills required for the specialty surgeries for which he or she may be required to circulate or scrub;
- Many ORs require that the nurse "take call," a role that calls for an expanded knowledge and skill set of independent nursing action for urgent and emergent situations; and

- In this unique working environment, most of the working hours of the nurse's day are enacted on stage with an audience.

Common factors associated with a failure to properly provide best practices to patients by novice nurses include the high incidence of patient mortality, burnout, incivility, and a decreased desire to thrive in the nursing profession. ${ }^{[12]}$ 
Research states that approximately $31 \%$ of nurses attribute incivility as a driving force of increased turnover rates. ${ }^{[13]}$ According to Willemsen-McBride, it is estimated that approximately $35 \%$ to $65 \%$ of new graduates will leave their work place within the first year of employment, lending to the $55 \%$ nursing turnover rate. ${ }^{[14]}$ The perioperative environment is a difficult place for novice nurses to fit in, unless there is a concerted effort from both staff members and leaders to embrace the novice nurse's desire to learn. ${ }^{[15]}$ Providing a strong and confidential support system allows the novice nurse to provide feedback on the orientation process. Once feedback is provided, revised action plans must be created through a collaborative effort between the nurse educator and the novice nurse.

According to the Texas Department of State Health Services, Texas faces a nursing shortage that is more severe than the national average. ${ }^{[16]}$ This has caused the state to maintain a higher turnover and vacancy rate than those in other parts of the nation, and in 2015, reporting RN turnover trends were at $23.6 \% .^{[16]}$ Amidst this shortage, through targeted efforts such as the HMH OR nurse residency program, $\mathrm{HMH}$ is able to maintain a lower turnover rate. Of the individuals observed in 2014, 85\% were retained after 2 years (there were no turnover in the first 18 months), with $91 \%$ of those retained maintaining an OR role.

\section{Conclusion}

There is a shortage of perioperative nurses, and the demand for perioperative nurses in the United States is growing steadily by $1 \%$ to $2 \%$ each year. ${ }^{[2]}$ There is a growing demand for OR nurses that far outweighs the supply. Also, once nurses are recruited, as much effort has to be given for retention. The partnership with nursing schools continues in an effort to allow exposure to the OR setting prior to graduation. The HMH OR nurse residency program is continuously refined based on evidence-based practice and feedback from the graduate nurse participants. Specialty educators play a paramount role in ensuring a valuable experience as the novice nurse transitions into practice. As nurse educators, it is important to create a healthy orientation environment for the novice nurse during the transition from novice to expert. The benefits of a healthy orientation process and environment are increased retention, decreased turnover, and optimum patient outcomes.

\section{ACKNOWLEDGEMENTS}

We would like to acknowledge Jennifer Holmes for her editorial support as a freelance medical writer.

\section{Conflicts of InTERest Disclosure}

The author declares that there is no conflict of interest.

\section{REFERENCES}

[1] Monahan JC. A student nurse experience of an intervention that addresses the perioperative nursing shortage. J Perioper Pract. 2015; 25(11): 230-234. PMid:26721129

[2] Ball K, Doyle D, Oocumma NI. Nursing shortages in the OR: solutions for new models of education. AORN J. 2015; 101(1): 115-136. https://doi.org/10.1016/j.aorn.2014.03.015

[3] Renter M, Allen A, Thallas A, et al. How Magnet [R] designation affects nurse retention: an evidence-based research project: a positive work environment and nurse satisfaction can improve nurse retention. Am Nurse Today. 2014; 9(3).

[4] Zinn JL, Guglielmi CL, Davis PP, et al. Addressing the nursing shortage: the need for nurse residency programs. AORN J. 2012; 96(6): 652-657. https://doi.org/10.1016/j. aorn. 2012.09.011

[5] Dumchin M. Redefining the future of perioperative nursing education: a conceptual framework. AORN J. 2010; 92(1): 87-100. https://doi.org/10.1016/j . aorn.2009.11.068

[6] Perioperative nursing: OR education. Kai Tiaki Nursing New Zealand. 2015; 21(1): 36-36.

[7] Penz KL, Bassendowski SL. Evidenced-based nursing in clinical practice: implications for nurse educators. J Contin Educ Nurs. 2006; 37(6): 250-254. https://doi.org/10.3928/00220124-20061 101-03

[8] Battié RN. Perioperative nursing and education: what the IOM future of nursing report tells us. AORN J. 2013; 98(3): 249-259. https://doi.org/10.1016/j.aorn.2013.07.004
[9] Cvetic E. Communication in the perioperative setting. AORN J. 2011; 94(3): 261-270. https://doi.org/10.1016/j.aorn.2011.01 .017

[10] Claridge S. Reintroducing nursing students to the perioperative environment. Dissector. 2012; 40(3): 39-42.

[11] Graling P, Rusynko B. Kicking it up a notch - successful teaching techniques. AORN J. 2004; 80(3). https://doi.org/10.1016/ S0001-2092 (06) 60538-3

[12] Laschinger HK, Wong C, Regan S, et al. Workplace incivility and new graduate nurses mental health: the protective role of resiliency. J Nurs Adm. 2013; 43(8): 415-421. PMid:23892307 https://doi.org/10.1097/nna.ob013e31829d61c6

[13] Simons S. Workplace bullying experienced by Massachusetts Registered Nurses and the relationship to intention to leave organization. ANS Adv Nurs Sci. 2008; 31(2): E48-E59. https : //doi .org/10 .1097/01. ANS.0000319571.37373.d7

[14] Willemsen-McBride T. Preceptorship planning is essential to perioperative nursing retention: matching teaching and learning styles. Can Oper Room Nurs J. 2010; 28(1): 8-8, 10-11, 16 passim.

[15] Wilson G. Redesigning or orientation. AORN J. 2012; 95(4): 453 462. https://doi.org/10.1016/j. aorn.2012.01.022

[16] Texas Department of State Health Services. Texas Center for Nursing Workforce Studies Hospital Nurse Staffing Survey. EPublication: E25-14476; 2014. 